\title{
Sample Preparation in Ion-chromatography
}

\author{
William F. Koch \\ Center for Analytical Chemistry, National Bureau of Standards Washington, D.C. 20234
}

(January 22, 1979)

\begin{abstract}
Ion-chromatography, a relatively new technique in analytical chemistry, has already shown great promise toward solving complex trace analysis problems, in particular the speciation and quantitation of anions. It is especially attractive to the field of microanalysis. The method of sample preparation, however, is crucial in order to realize this capacity. Existing microanalytical methods nearly always must be modified to be compatible with ion-chromatography, and often, more extensive sample cleanup is required than is needed for "single species" methods. These considerations have been applied to the determination of chloride and bromide in waste oil, and to the analysis of oyster tissue. Pretreatment with polystyrene resin and ion-exchange resin is discussed.
\end{abstract}

Key words: Conductivity; ion-chromatography; ion-exchange; liquid chromatography; oil; oyster.

\section{Introduction}

Ion-chromatography (IC) is a new liquid chromatographic technique based on the ion-exchange separation of ionic species followed by conductimetric detection; the high background conductance associated with the eluent is made negligible through use of a suppressor resin column [1]. ${ }^{1}$ This technique has already shown great promise toward the solution of complex trace analysis problems [2], in particular the speciation and quantitation of species existing in or able to be converted to anionic form. The potential of ionchromatography to determine several species simultaneously (fig. 1) is especially attractive to the field of microanalysis.

\section{ION-CHROMATOGRAPHY STANDARD}

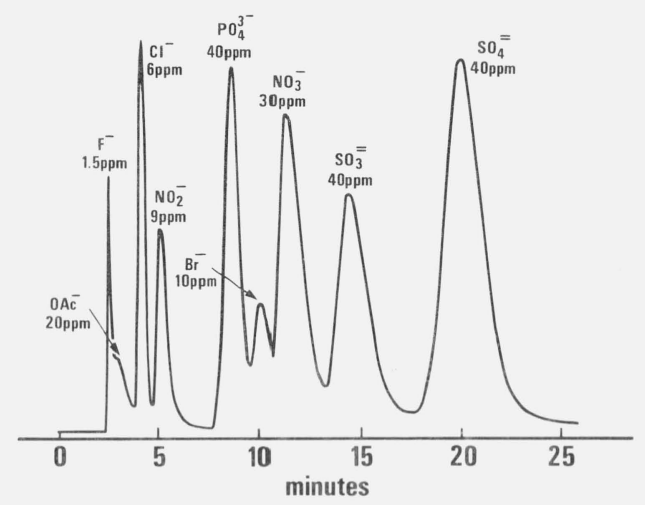

Figure 1.
However, the method of sample preparation is crucial in order to realize this potential. Existing microanalytical methods nearly always must be modified to be compatible with ion-chromatography, and often, more extensive sample cleanup is required than is needed for "single-species" methods. Five major requirements for sample preparation for anion analysis have been identified (table 1) and will be discussed first in general form and then as applied to the analyses of oysters and waste oil.

TABLE 1. Requirements for Sample Preparation in Ion-Chromatography
1. In Solution
2. No Acid Added
3. Minimal Base, $\mathrm{pH}<11$
4. Minimal Blank Correction
5. Filterable

\section{Requirements}

Since ion-chromatography is a form of liquid chromatography, the sample to be analyzed obviously must be in solution, preferably a predominantly aqueous solution. There are some instances in which it may be advantageous to use methanol or some other organic solvent for initial solubilization of anions; however, it is recommended that such action be followed with a large dilution with water or an extraction into water.

Many samples are already in solution, such as rainwater. Those that are not, particularly those not readily soluble in water or those that are in an organic matrix, pose a vexing problem. No acids may be used, as that would add large amounts of anions to the analyte which would exceed the

${ }^{1}$ Figures in brackets indicate literature references at the end of this paper. 
capacity of the analytical column. Hence wet-ashing with strong acids, a very popular sample preparation technique, is not compatible with ion-chromatography.

On the other hand, excess base also must be avoided for two reasons. First, hydroxide ion causes a negative excursion from the baseline as it elutes from the ion-chromatographic columns. This dip in the baseline destroys meaningful data for the early eluting anions. Second, the hydroxide ion is itself a strong eluent and as such speeds other anions through the column, changing their retention times and adversely affecting resolution. It is advised that the $\mathrm{pH}$ of the analyte solution be below 11 . This severely restricts the use of dryashing with a basic flux.

An obvious requirement, but nevertheless one with considerable impact in ion-chromatography, is the need to keep reagent blanks to a minimum. It is relatively easy to obtain "heavy-metal-free" reagents, but virtually impossible to get anion-free reagents. This is a serious problem for ionchromatography and drastically limits the chemistry that can be performed on the sample.

The final consideration is filterability of the analyte solution. It is strongly recommended that the analyte solution pass through a sub-micrometer filter before injection into the ion-chromatograph to protect the rather expensive analytical columns.

\section{Oyster Analysis}

The analysis of lyophilized oyster tissue illustrates all five points. The scope of the project was to detect and quantitate as many anionic species as possible by using ion-chromatography. It was intended to look at both the anions soluble in water and those anions resulting from a suitable combustion or digestion technique.

To determine the solubles, $50 \mathrm{~mL}$ of standard eluent (see table 2) was added to a $0.5 \mathrm{~g}$ sample of lyophilized oyster tissue in a test tube and sonicated for $30 \mathrm{~min}$ in a $50^{\circ} \mathrm{C}$ water bath. The resulting gelatinous solution was hardly suitable for IC analysis; and attempts to clarify the solution by decantation, centrifugation, coagulation, or absorption on polystyrene resin all met with failure. A series of filtrations did yield enough sample for a single injection into the IC.

TaBle 2. Standard Ion-Chromatographic Conditions at the National Bureau of Standards

\begin{tabular}{|c|c|}
\hline Eluent: & (E3) $0.003 \mathrm{~mol} / \mathrm{L} \mathrm{NaHCO}_{3} / 0.0018 \mathrm{~mol} / \mathrm{L} \mathrm{Na}_{2} \mathrm{CO}_{3}$ \\
\hline Flow Rate: & $2.5 \mathrm{~mL}$ per minute ( 25 percent pump rate) \\
\hline Separator Column: & $\begin{array}{l}3 \times 150 \mathrm{~mm} \text { anion pre-column plus } 3 \times 500 \mathrm{~mm} \text { anion } \\
\text { separator column }\end{array}$ \\
\hline Suppressor Column: & $6 \times 250 \mathrm{~mm}$ anion suppressor column \\
\hline Injection Volume: & 100 microliters \\
\hline
\end{tabular}

The series of filters used was coarse paper (Whatman \#541)*, then slow paper (Whatman \#42), and finally a Millipore syringe filter $(0.22$ micrometer). The chromatogram, run under standard conditions (table 2), is shown in figure 2. The full-scale meter setting was in the logarithmic mode to ensure that all peaks would remain on scale. Six peaks were identified via a standard solution run under identical conditions. Quantitation was possible only on a very approximate level (table 3 ). Peak "a" is a composite of at least two species, indicated by the broadness of the peak; as a result, the fluoride concentration reported has a broad upper limit. The bromide and nitrate peaks ("d" and " $\mathrm{e}$ ") are not well-resolved at all, and the broad tailing suggests other species eluting at the same time. The broad peak eluting after sulfate is probably oxalate. Although only a partially successful experiment, this exercise demonstrates the requirement of filterability of the analyte. Injection of the gelatinous solution directly onto the analytical columns would have destroyed them.

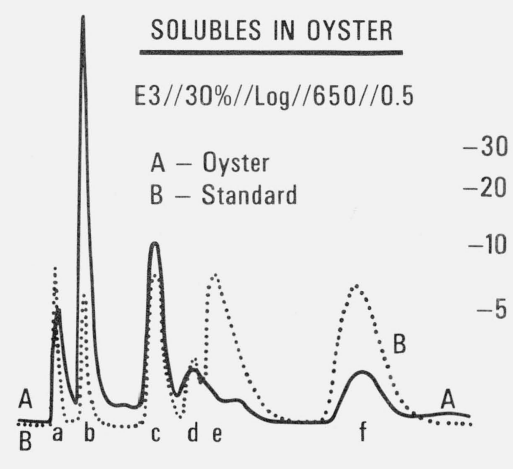

Figure 2.

Table 3

Solubles in Oysters

Peak Identification and Approximate Quantitation

$\begin{array}{ccc}\text { Peak } & \begin{array}{c}\text { Probable } \\ \text { Species }\end{array} & \begin{array}{c}\text { Approximate } \\ \text { Concentration }\end{array} \\ \text { a } & \mathrm{F}^{-} & <0.02 \% \\ \mathrm{~b} & \mathrm{Cl}^{-} & 1.1 \% \\ \mathrm{c} & \mathrm{PO}_{4}^{3-} & 0.7 \% \\ \mathrm{~d} & \mathrm{Br}^{-} & <0.09 \% \\ \mathrm{e} & \mathrm{NO}_{3}^{-} & <0.13 \% \\ \mathrm{f} & \mathrm{SO}_{4}^{-} & 0.19 \%\end{array}$

* Certain commercial equipment, instruments, or materials are identified in this paper in order to specify the experimental procedure. In no case does such identification imply recommendation or endorsement by the National Bureau of Standards, nor does it imply that the material or equipment is necessarily the best available for the purpose. 
Determination of total anionic species requires destruction of the organic matrix. Wet-ashing with strong acid is not allowed for the reasons outlined above. Dry-ashing with Eschka mixture proved unsatisfactory due to the resultant high concentration of alkali as well as a large blank correction. Combustion in a high-pressure oxygen bomb also was unsatisfactory for the analysis of oyster tissue because of difficulties in achieving complete combustion. Satisfactory results were obtained using the Schöniger oxygen flask [3].

A commercial Schöniger flask setup was used: $500 \mathrm{ml}$ flask with ball and socket joint stopper, platinum sample basket, black combustion paper, and an infrared ignitor. Various scrubber solutions were tried; distilled water proved to be the most satisfactory. Use of the standard carbonate eluent as scrubber solution was unacceptable because it favored nitrite formation (which can interfere with chloride) and sulfite formation. Addition of hydrogen peroxide to the carbonate solution overcame the problem of incomplete oxidation of sulfur. However, hydrogen peroxide contains a number of fast eluting impurities and this results in a horrendous blank problem. Therefore, $20 \mathrm{~mL}$ of distilled water was used in each combustion; oyster sample size ranged from 10 to $30 \mathrm{mg}$.

After combustion and absorption of the gases into the scrubber solution, the sample was filtered and injected into the ion-chromatograph under standard conditions (fig 3). To achieve better resolution of the chloride peak from nitrite, the flow rate was reduced to $0.8 \mathrm{~mL}$ per minute $(10$ percent pump rate). Chlorine as chloride and sulfur as sulfate were

\section{OYSTER}

$17.33 \mathrm{mg}$ combusted in Schoniger flask

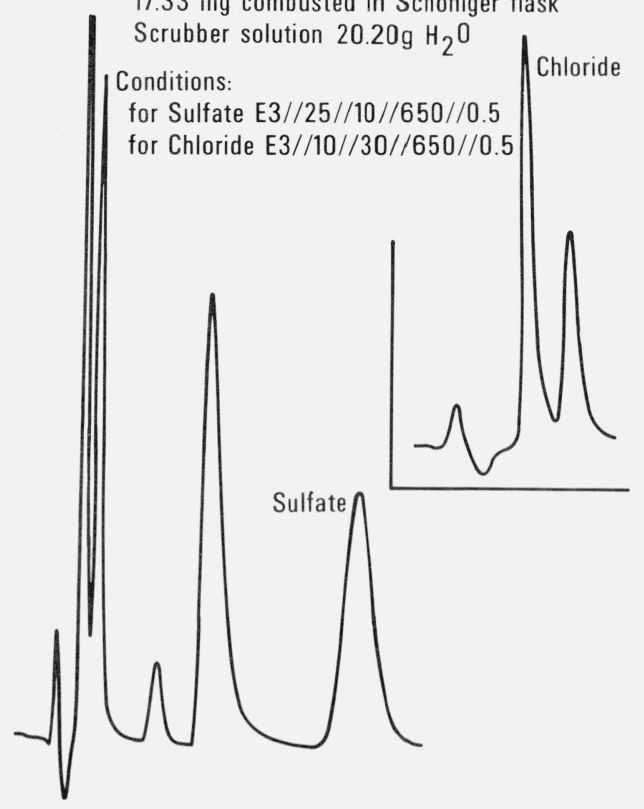

Figure 3. the only two species able to be quantitated. Nitrogen determination was confused because of its various oxidation states. Fluoride was buried in the blank from the combustion paper. Phosphate was irreproducible and bromide was swamped by the large nitrate peak. Standard solutions of chloride and sulfate (in a matrix of fluoride, nitrite, phosphate, and nitrate to simulate the combusted oyster sample) were made up by weight and analyzed on the IC under identical conditions. Blanks of the scrubber solution and black combustion paper (fig. 4) were also analyzed and the appropriate corrections were applied to obtain the final results shown in table 4.

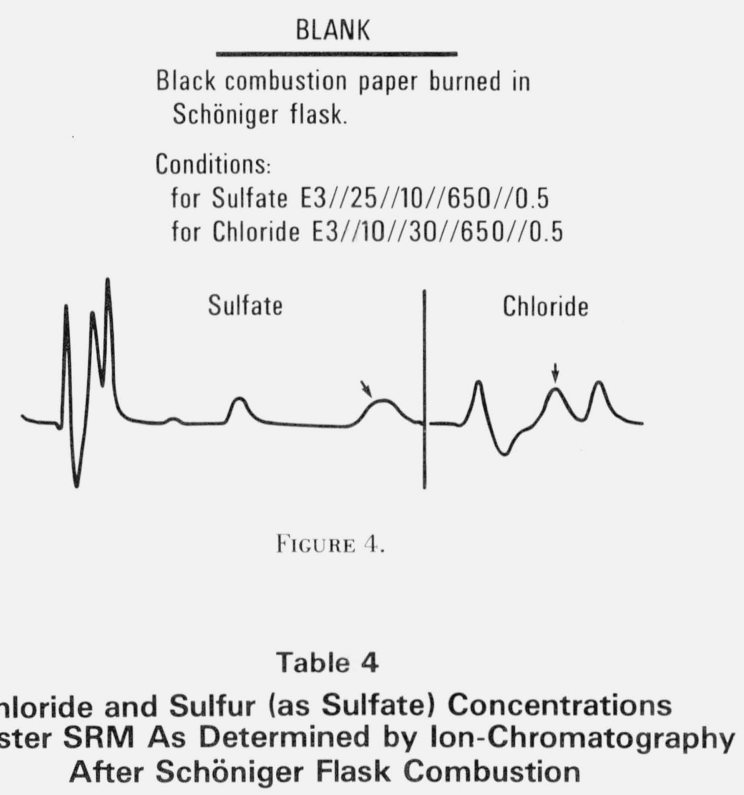

\begin{tabular}{|c|c|c|c|}
\hline Sample Wt. & $\begin{array}{l}\text { Scrubber } \\
\text { Soln. Wt. }\end{array}$ & Chloride & Sulfate \\
\hline $11.59 \mathrm{mg}$ & $20.10 \mathrm{~g}$ & $1.034 \%$ & $2.201 \%$ \\
\hline 24.36 & 20.07 & 1.032 & 2.259 \\
\hline 19.80 & 20.00 & 1.057 & 2.244 \\
\hline 12.05 & 19.99 & 1.010 & 2.253 \\
\hline 18.32 & 19.99 & 1.037 & 2.258 \\
\hline 17.33 & 20.20 & 1.051 & 2.278 \\
\hline 26.67 & 19.99 & 1.038 & --- \\
\hline \multirow[t]{3}{*}{20.11} & 20.02 & 1.013 & 2.300 \\
\hline & Stc & $\begin{array}{l}1.034 \% \\
0.016\end{array}$ & $\begin{array}{l}2.256 \% \\
0.031\end{array}$ \\
\hline & Rel. Stc & $1.6 \%$ & $1.4 \%$ \\
\hline
\end{tabular}

\section{Waste Oil Analysis}

The analysis of waste oil serves to demonstrate how an existing microanalytical sample preparation technique must be modified in order to be compatible with ion-chromatography. The purpose of the project was to measure total chloride and total bromide in used crankcase oil. 
The prescribed method for solubilization of the chloride and bromide in oil is American Society for Testing and Materials (ASTM) Procedure D 1317-IP 118, Sodium Alcoholate Method [4]. Briefly, this procedure calls for refluxing the oil sample with petroleum ether, butanol and sodium metal; acidifying with nitric acid, extracting into water; diluting to a known volume; and determining the chloride and bromide by a suitable analytical method. The result of injection into the IC under standard conditions of a sample prepared using this method is shown in figure 5. The high nitrate concentration from the acidification step has overloaded the analytical column, rendering the chomatographic analysis useless.

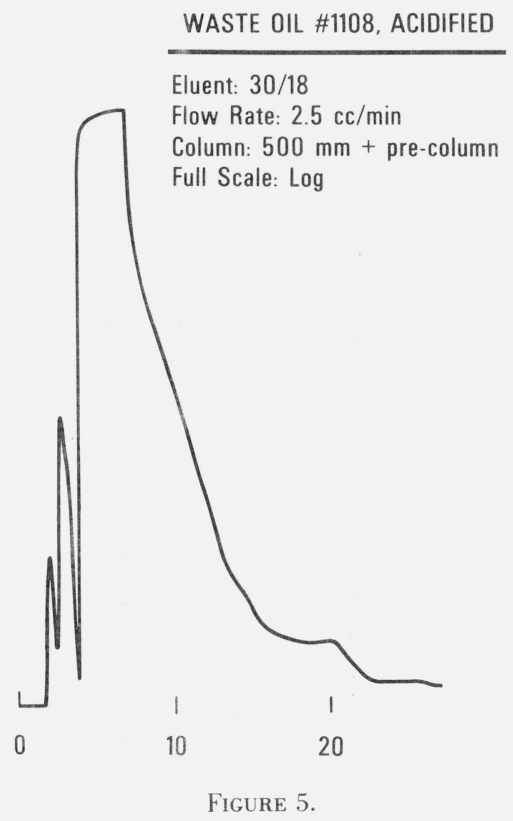

Figure 6 is the chromatogram of another sample of oil prepared according to the ASTM procedure with the acidification step deleted. The solution, being a somewhat cloudyyellow, and with an organic odor, was passed through a column of Amberlite XAD-2 polstyrene resin and filtered before injection. The $\mathrm{pH}$ of the solution was over 13 . No useful quantitative information is obtained for either chloride (eluting at 4 minutes) or bromide (eluting at 10 minutes). The chloride peak is obscured by peaks associated with carbonate and butylate; the hydroxide dip further confuses the interpretation. The bromide is not well-resolved from either the preceding or succeeding peak; hence, a meaningful baseline cannot be drawn.

To remedy these problems, further sample preparation was required. The solution was passed through a column containing strong-acid cation exchange resin $\left(\mathrm{H}^{+}\right.$form). This procedure neutralized the hydroxide ion, removed the butylate, and reduced the concentration of carbonate as shown in the chromatogram in figure 7 . In order to resolve the chloride and bromide more completely, chromatographic conditions

\section{WASTE OIL \#1127}

Eluent: $30 / 18$

Flow Rate: $2.5 \mathrm{cc} / \mathrm{min}$

Column: $500 \mathrm{~mm}+$ pre-column

Full Scale: 10 micromhos

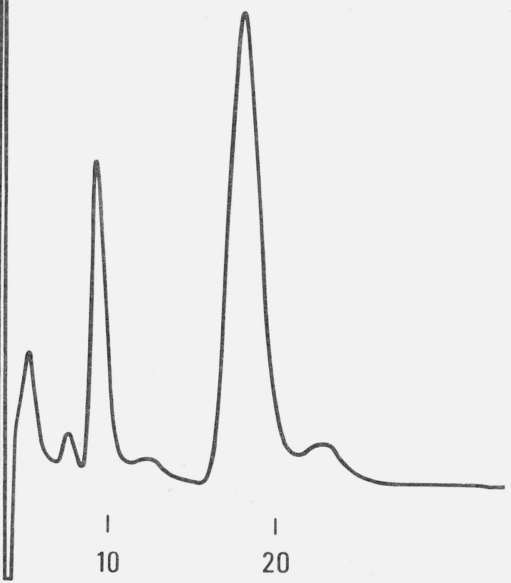

Figure 6.

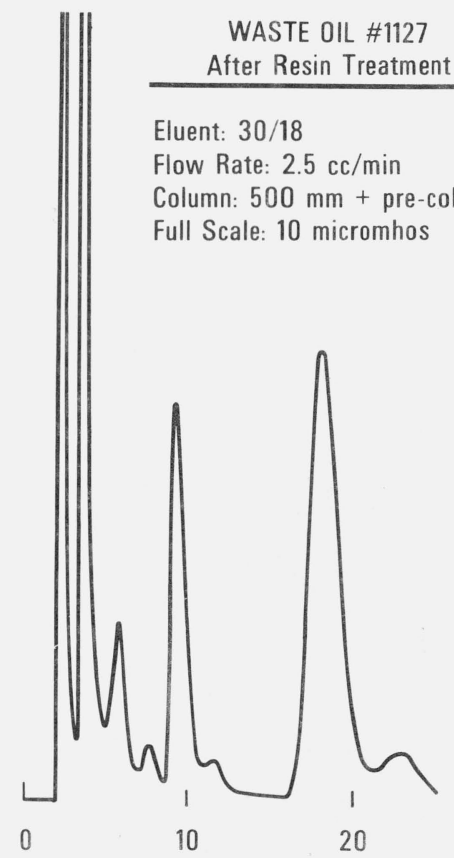

Figure 7. 
were changed slightly; a weaker eluent, $0003 \mathrm{~mol} / \mathrm{L} \mathrm{NaHCO}_{3}$ was used (fig. 8). Under these conditions, chloride elutes at $7 \mathrm{~min}$; bromide elutes at $23.5 \mathrm{~min}$. Standards of chloride and bromide were prepared which bracketed the concentrations of chloride and bromide in the oil sample solution and were analyzed under identical chromatographic conditions (figure 9). Results of this analysis are shown in table 5. The ionchromatographic (IC) values are in good agreement with those obtained by neutron activation analysis (NAA).

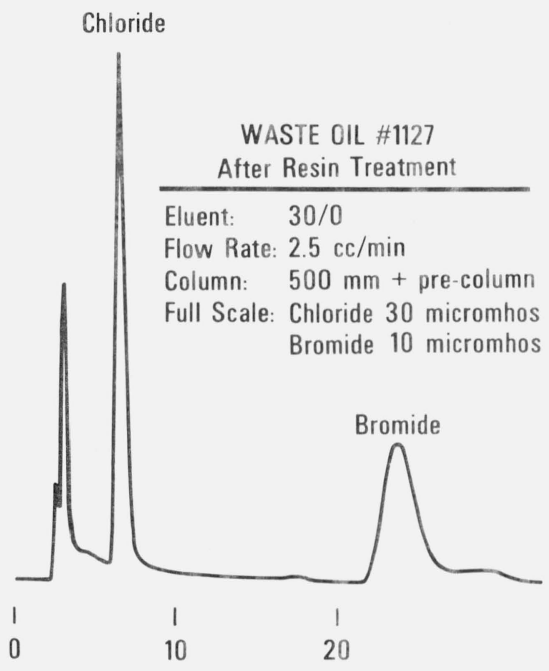

Figure 8.

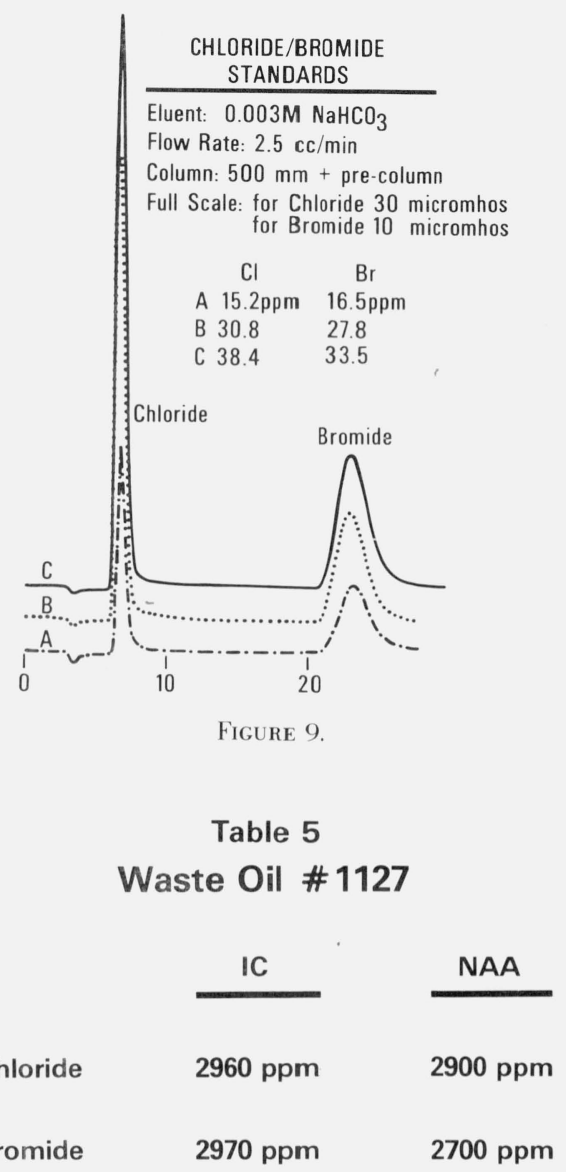

\section{References}

[1] Small, H., Stevens, T. S., and Bauman, W. C. "Novel Ion-Exchange

Ion-chomatography has definite potential in the field of microanalysis and its use should be fully exloited. However, it must be kept in mind that the input requirements of the ion-chromatograph are unique and rather inflexible, so that for IC to realize its full potential, the classical sample preparation procedures must often be revised or new methods be developed. Chromatographic Method Using Conductimetric Detection,"Anal. Chem. 47, 1801 (1975).

\section{Conclusion}

[2] Ion Chromatographic Analysis of Environmental Pollutants, E. Sawicki, J. D. Mulik, and E. Wittgenstein, ed., Ann Arbor Science Publishers Inc., Ann Arbor, MI (1978).

[3] W. Schöniger, "De mikroanalytische Schnellbestimmung von Halogenen und Schwefel in organischen Verbindungen," Mikrochim. Acta, 869 (1956).

[4] 1968 Book of American Society for Testing and Materials Standards, 1 7, 498 (1968). 